\title{
BMJ Open Socioeconomic inequality in health domains in Tehran: a population-based cross-sectional study
}

\author{
Vali Baigi, ${ }^{1}$ Saharnaz Nedjat, ${ }^{2}$ Ahmad Reza Hosseinpoor, ${ }^{3}$ Majid Sartipi, ${ }^{4}$ \\ Yahya Salimi, ${ }^{5}$ Akbar Fotouhi ${ }^{6}$
}

To cite: Baigi V, Nedjat S, Hosseinpoor AR, et al. Socioeconomic inequality in health domains in Tehran: a population-based crosssectional study. BMJ Open 2018;8:e018298. doi:10.1136/ bmjopen-2017-018298

- Prepublication history for this paper is available online. To view these files, please visit the journal online (http://dx.doi. org/10.1136/bmjopen-2017018298).

Received 20 June 2017 Revised 29 December 2017 Accepted 2 January 2018
Check for updates

For numbered affiliations see end of article.

Correspondence to Dr Saharnaz Nedjat; nejatsan@tums.ac.ir

\section{ABSTRACT}

Objective Reduction of socioeconomic inequality in health requires appropriate evidence on health and its distribution based on socioeconomic indicators. The objective of this study was to assess socioeconomic inequality in various health domains and self-rated health (SRH).

Methods This study was conducted using data collected in a survey in 2014 on a random sample of individuals aged 18 and above in the city of Tehran. The standardised World Health Survey Individual Questionnaire was used to assess different health domains. The age-adjusted prevalence of poor health was calculated for each health domain and SRH based on levels of education and wealth quintiles. Furthermore, the Slope Index of Inequality (SII) and the Relative Index of Inequality (RII) were applied to assess socioeconomic inequality in each of the health domains and SRH.

Results The age-adjusted prevalence of poor health was observed in a descending order from the lowest to the highest wealth quintiles, and from the lowest level of education to the highest. RII also showed varying values of inequality among different domains, favouring rich subgroups. The highest wealth-related RIl was observed in the 'Mobility' domain with a value of $4.16(95 \% \mathrm{Cl} 2.01$ to 8.62), and the highest education-related RII was observed in the 'Interpersonal Activities' domain with a value of 6.40 (95\% Cl 1.91 to 21.36).

Conclusions Substantial socioeconomic inequalities were observed in different health domains in favour of groups of better socioeconomic status. Based on these results, policymaking aimed at tackling inequalities should pay attention to different health domains as well as to overall health.

\section{INTRODUCTION}

Based on the WHO's recommendations, one of the main parts of assessing the performance of health systems is to measure health inequalities. ${ }^{1}$ Many of these inequalities, which are a result of socioeconomic differences between different groups of people, are unfair. $^{2}$ Socioeconomic inequality in health is a major challenge in public health ${ }^{3}$ and is seriously under consideration by policymakers and researchers. ${ }^{4}$ All over the world, evidence suggests that people of poorer

\section{Strengths and limitations of this study}

The study design is cross-sectional, hence can only describe associations between socioeconomic indicators and health domains.

- The health domains have been measured with selfrated information, and clinical examinations have not been performed to evaluate them.

- Inequality in health is multidimensional, and the magnitude of inequalities may change depending on the socioeconomic indicators used. The present study measured socioeconomic inequality by various indicators

- To the best of our knowledge, this is the first study in Iran to investigate socioeconomic inequality in various health domains.

socioeconomic status (SES) suffer from lower levels of health. ${ }^{5}$

Based on the definition given by the WHO, health is a multidimensional concept. ${ }^{6}$ Hence, to determine the status of health and to assess the impact of health interventions, we must first evaluate the health status of individuals from all its aspects. Self-rated health $(\mathrm{SRH})$ is a health indicator that is usually employed in research on socioeconomic inequalities. ${ }^{7}$ Studies indicate that SRH may predict outcomes such as disability, morbidity and morbidity, and cardiovascular diseases. ${ }^{8}$ Although SRH has shown good reliability in indicating a society's health, its utilisation as a public health measure for inequality studies has led to underestimation of inequality among different socioeconomic groups. ${ }^{10}$ The WHO has outlined eight main health domains for individuals in its World Health Survey (WHS) Individual Questionnaire, irrespective of their SES: mobility, self-care, cognition, interpersonal activities, vision, sleep and energy, pain and discomfort, and affect. ${ }^{11}$

In the WHS conducted between 2002 and 2004, different health domains were measured in different countries, ${ }^{12}$ and using 
the same data socioeconomic inequality was investigated as well. ${ }^{11}$

In Iran too, studies have been conducted in the field of socioeconomic inequality on different health outcomes including SRH. ${ }^{13}$ However, to our knowledge, no study has been conducted on the socioeconomic inequality of different health domains. The current study therefore attempts to investigate the latter using the standardised WHO tool and to compare it with SRH socioeconomic inequality.

\section{METHODS}

This study used the data of the survey conducted in 2014 on Tehran's residents aged 18 and above. The individuals were selected using multistage sampling. The city of Tehran is divided into 22 municipal districts as strata. Proportional to the population size of each district, a number of blocks were randomly chosen. From each block, 10 households were systematically selected and only one person was interviewed from each household. The respondent was selected from all eligible individuals of the household through quota sampling for age and gender. Face-to-face interviews were held with the respondents at their doorsteps at times when all members of the household would most likely be at home, to maximise the possibility of including all age and gender groups. Overall, 2987 households were visited to collect data, of which, eventually, 1995 households (individuals) were interviewed (response rate $=66.9 \%$ ). Data were collected by 10 teams of questioners, each consisting of four trained questioners. All the questioners had a bachelor's or higher academic degree. For quality control purposes, the execution of the project was monitored by four teams. First, the objectives of the study were explained clearly, and then participants with informed consent were included in the study.

\section{Data collection tool}

To assess the different domains of health, we used the WHS Individual Questionnaire, which has been translated and standardised in Iran. ${ }^{14}$ The intraclass correlation of the questionnaire was $0.89 .^{14}$ This questionnaire assesses an individual's health status in eight domains, namely mobility, self-care, cognition, interpersonal activities, vision, sleep and energy, pain and discomfort, and affect.

The respondents were asked to report the extent of their problems in each domain by selecting one of the five options of none, mild, moderate, severe and extreme/ cannot do. The individuals fell into one of the groups of good health (if either option of none, mild or moderate was chosen) and/or poor health (if either severe or extreme was chosen). ${ }^{11}$

The individuals' SRH was measured with the standard question: 'In general, how would you rate your health today?' Those who rated their health as 'bad' or 'very bad' were assigned to the 'poor health' group, while those who rated their health as 'very good', 'good' or 'moderate' were classified as the 'good health' group. ${ }^{1315}$

To assess the economic status of individuals, principal component analysis (PCA) ${ }^{16} 17$ was applied to the net assets of each household, and the household wealth index was created. The PCA conducted on variables of assets and household data included owning a car (not for money-making purposes), motorcycle (not for moneymaking purposes), cellphone, freezer, dishwashing machine, microwave oven, personal computer, vacuum cleaner, washing machine, having a bath in the house, colour television, any type of video player (VHS, VCD, DVD and others), and per capita number of bedrooms and per capita area of residence. In PCA, the first component justifies the greatest share of total variance among the variables, hence is considered as the wealth index of each household. ${ }^{18}$

In this study, the first component justified $25.2 \%$ of the total variance. Based on the PCA results, individuals were classified into five groups of lowest to highest economic status.

From the standpoint of years of education received, the participants were grouped into no formal education, primary ( $1-5$ years), intermediate ( $6-8$ years), high school (9-12 years) and tertiary (13 years or more).

Moreover, data on age, sex and marital status (single, married, separated, widow) were also collected.

\section{Statistical analysis}

The age-adjusted prevalence of poor health was calculated for each of the health domains and SRH based on educational level and economic status. Moreover, the Slope Index of Inequality (SII) and the Relative Index of Inequality (RII) were used to assess the absolute and relative socioeconomic inequality, respectively, in each of the eight health domains and SRH. RII and SII are regression-based measures of socioeconomic inequality. ${ }^{19}$

To calculate the RII and SII on grounds of SES, the individuals were ranked (from the highest to the lowest wealth index or educational status); the highest and lowest values ranked 0 and 1 , respectively. ${ }^{20}$ RII represents the ratio of poor health among individuals at the highest relative inequality related to assets rank (ie, the lowest level of education or wealth) to those who are ranked at 0 (the highest level of education or wealth), taking into account the entire distribution of SES. ${ }^{11}$ An RII greater than 1 indicates that the prevalence of poor health among people of low SES is greater. SII is a measure of the difference in health among individuals at the highest relative inequality related to assets rank to those who are ranked at 0 , taking into account the entire distribution of SES.

In model 1, age-adjusted SII and RII were calculated. In model 2 we only calculated RII, and in this model, in addition to age, to estimate pure effect of each of wealth index or education variables, sex, marital status, and wealth index or education were also adjusted. To adjust for the population distribution, poststratification corrections were made to sampling weights. However, the design 
Table 1 Age-adjusted prevalence of poor health across health domains and self-rated health among adults aged 18+, by wealth and education

\begin{tabular}{|c|c|c|c|c|c|c|c|c|c|c|c|c|c|c|c|c|c|c|}
\hline & \multicolumn{2}{|c|}{$\begin{array}{l}\text { Self-rated } \\
\text { health }\end{array}$} & \multicolumn{2}{|c|}{ Mobility } & \multicolumn{2}{|c|}{ Self-care } & \multicolumn{2}{|c|}{$\begin{array}{l}\text { Pain and } \\
\text { discomfort }\end{array}$} & \multicolumn{2}{|c|}{ Cognition } & \multicolumn{2}{|c|}{$\begin{array}{l}\text { Interpersonal } \\
\text { activities }\end{array}$} & \multicolumn{2}{|c|}{ Vision } & \multicolumn{2}{|c|}{$\begin{array}{l}\text { Sleep and } \\
\text { energy }\end{array}$} & \multicolumn{2}{|c|}{ Affect } \\
\hline & $\%$ & SE & $\%$ & SE & $\%$ & SE & $\%$ & SE & $\%$ & SE & $\%$ & SE & $\%$ & SE & $\%$ & SE & $\%$ & SE \\
\hline Wealth quintile 1 & 16.4 & 1.4 & 18.2 & 1.6 & 3.4 & 0.7 & 20.5 & 1.6 & 11.1 & 1.3 & 4.8 & 0.9 & 2.8 & 0.6 & 15.9 & 1.5 & 19.9 & 1.6 \\
\hline Wealth quintile 2 & 11.7 & 0.7 & 13.2 & 0.8 & 2.6 & 0.4 & 15.4 & 0.9 & 8.6 & 0.7 & 4.1 & 0.5 & 2.6 & 0.4 & 13.7 & 0.9 & 17.0 & 1.0 \\
\hline Wealth quintile 5 & 3.8 & 0.7 & 4.4 & 0.7 & 1.1 & 0.4 & 5.8 & 0.9 & 3.9 & 0.7 & 2.4 & 0.6 & 2.2 & 0.6 & 8.4 & 1.1 & 10.2 & 1.2 \\
\hline $\begin{array}{l}\text { No formal } \\
\text { education }\end{array}$ & 23.1 & 2.9 & 23.9 & 3.1 & 4.2 & 1.0 & 35.1 & 3.7 & 17.2 & 3.0 & 8.6 & 2.3 & 2.3 & 0.8 & 17.4 & 2.7 & 22.5 & 3.0 \\
\hline Primary & 16.4 & 1.5 & 17.7 & 1.7 & 3.2 & 0.5 & 24.4 & 2.1 & 12.5 & 1.6 & 6.2 & 1.1 & 2.4 & 0.6 & 15.1 & 1.7 & 19.4 & 1.8 \\
\hline Intermediate & 11.3 & 0.8 & 12.7 & 0.8 & 2.5 & 0.3 & 16.1 & 1.0 & 8.9 & 0.8 & 4.4 & 0.6 & 2.5 & 0.4 & 13.1 & 0.9 & 16.7 & 1.1 \\
\hline
\end{tabular}

effects of health outcomes that were close to one ${ }^{21}$ were not taken into account in the analysis.

Statistical analysis was done using Stata V.12.

\section{RESULTS}

The mean age of the participants was 41.8 years (range=18-90; SD=15.45). Thirty-six per cent of the participants had received tertiary education. Table 1 shows the age-adjusted prevalence of poor health in different health domains and SRH. The lowest age-adjusted prevalence of poor health was observed in the 'SelfCare' domain $(2.5 \%)$, while the highest prevalence was seen in the 'Affect' domain (14.7\%). Moreover, overall, the age-adjusted prevalence of poor health was higher in people with no formal education and the poorest wealth quintile (table 1).
Table 2 illustrates the wealth-related SII and RII in poor health for different health domains and SRH. In model 1, age-adjusted SIIs for most domains are statistically significant. Accordingly, the difference in the prevalence of poor health in the 'Mobility' domain between the lowest wealth quintile and the highest wealth quintile is $12 \%$. In model 1, age-adjusted RII is greater than 1 and statistically significant in all domains but 'Vision'. The range of statistically significant RII was 2.35 for the sleep and energy domain, to 6.4 for the mobility domain. According to the results of this model, the prevalence of poor health in the 'Mobility' domain in the lowest wealth quintile was 6.4 times the prevalence of poor health in the highest wealth quintile $(\mathrm{P}<0.001)$. In addition SRH's RII was 6.83, which shows poor SRH was 6.83 as prevalent in the poorest compared with the richest people. Controlling

Table 2 Wealth-related inequality in poor health by health domains and self-rated health

\begin{tabular}{|c|c|c|c|}
\hline & Model $1^{*}$ & Model $1^{*}$ & Model 2† \\
\hline Health domains & SII $(95 \%$ Cl) & RII (95\% Cl) & RII (95\% Cl) \\
\hline Self-rated health & $0.05(0.01$ to 0.10$)$ & 6.83 (3.83 to 12.17$)$ & 3.86 (1.83 to 8.15$)$ \\
\hline Self-care & $0.01(-0.01$ to 0.02$)$ & 5.17 (1.25 to 21.32$)$ & $3.30(0.55$ to 19.59$)$ \\
\hline Pain and discomfort & $0.15(0.10$ to 0.21$)$ & 5.36 (3.29 to 8.70$)$ & 2.37 (1.32 to 4.24$)$ \\
\hline Interpersonal activities & $0.02(-0.01$ to 0.05$)$ & 2.56 (1.10 to 5.96$)$ & 1.08 (0.38 to 3.08$)$ \\
\hline Vision & $-0.001(-0.03$ to 0.03$)$ & 1.06 (0.54 to 3.57$)$ & 1.01 (0.48 to 3.80$)$ \\
\hline Sleep and energy & $0.09(0.03$ to 0.15$)$ & 2.35 (1.52 to 3.64$)$ & $2.20(1.28$ to 3.77$)$ \\
\hline Affect & $0.13(0.07$ to 0.19$)$ & 2.44 (1.62 to 3.61$)$ & 2.22 (1.37 to 3.54 ) \\
\hline
\end{tabular}

Bold indicates $\mathrm{P}<0.05$.

${ }^{*}$ Model 1 adjusted for age.

†Model 2 adjusted for age, sex, education and marital status.

RII, Relative Index of Inequality; SII, Slope Index of Inequality. 
Table 3 Education-related inequality in poor health by health domains and self-rated health

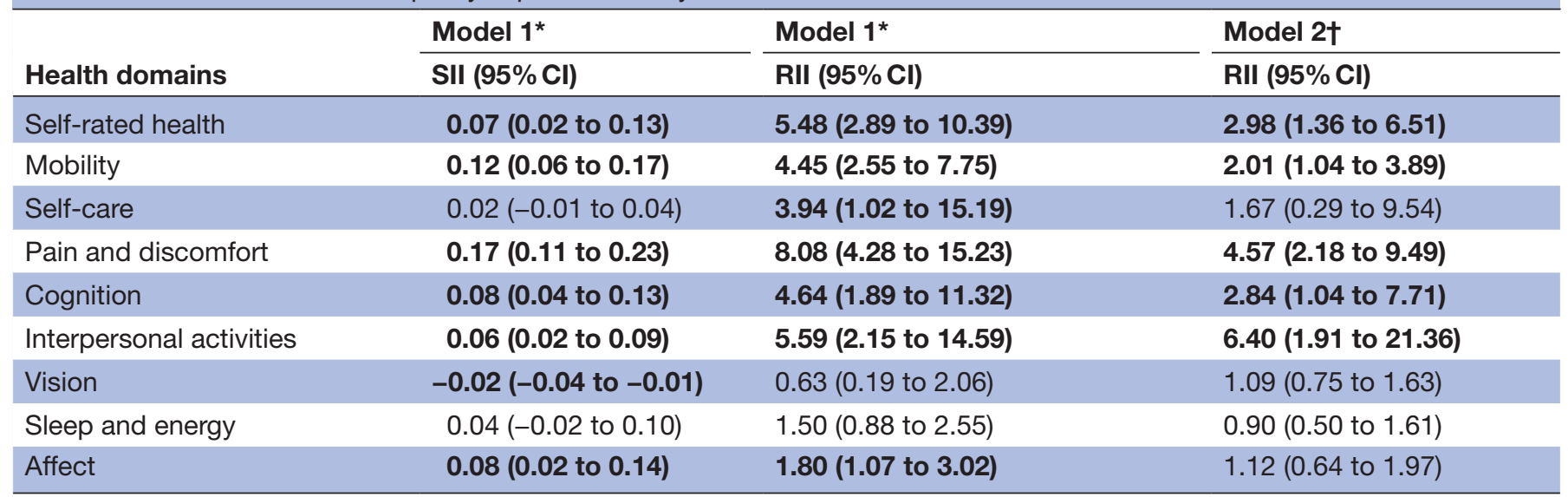

Bold indicates $\mathrm{P}<0.05$.

*Model 1 adjusted for age.

†Model 2 adjusted for age, sex, wealth and marital status.

RII, Relative Index of Inequality; SII, Slope Index of Inequality.

for age, sex, marital status and educational status in model 2 led to the weakening of inequality. Furthermore, in model 2, RII was statistically significant only for SRH and the domains of mobility, pain and discomfort, affect, and sleep and energy. Based on the results of this model, the prevalence of poor SRH in the lowest wealth quintile was 3.8 times that of the highest wealth quintile.

Table 3 shows the education-related SII and RII in poor health for different health domains and SRH. In model 1 , age-adjusted SII is statistically significant in all domains but 'Self-Care' and 'Sleep and Energy'. According to the results of this model, the difference in the prevalence of poor health in the 'Pain and Discomfort' domain between individuals with no formal education and those in tertiary education level is $17 \%$. In model 1, age-adjusted RIIs for all domains except for vision and sleep and energy were greater than 1 and statistically significant. The range of statistically significant RIIs was 1.80 for the affect domain, to 8.08 for the pain and discomfort domain. Based on these results, the prevalence of poor health in the pain and discomfort domain in individuals with no formal education was 8.08 times those with tertiary education level. Also, SRH's RII was 5.49, which shows poor SRH was 5.48 as prevalent in individuals with no formal education, compared with those in tertiary education level. In model 2, in addition to the effect of age, the effects of sex, marital status and wealth quintile were also adjusted. RII was greater than 1 and statistically significant for SRH and the domains of mobility, pain and discomfort, interpersonal activities, and cognition. Based on the results of this model, the prevalence of poor health in the interpersonal activities domain in people with no formal education was 6.40 as high in people with tertiary education level (0.003). There were no significant differences in sex distribution on the association between wealth index or education variables across all health domains and SRH $(\mathrm{P}>0.05)$.

\section{DISCUSSION}

To our best knowledge, this is the first study in Iran to examine and compare socioeconomic inequality in various health domains with that of overall SRH.

Based on our findings, the prevalence of poor health in the domains of mobility, pain and discomfort, cognition, sleep and energy, and affect was relatively higher in comparison with those in lower income countries from Hosseinpoor et al s study. ${ }^{11}$ However, the prevalence of poor SRH was lower in comparison with lower income countries. ${ }^{11}$ When compared with high-income countries, a higher prevalence of poor health in all domains and SRH was seen. ${ }^{11}$

Based on our results, different health domains have been unequally distributed among the residents of Tehran. For all health domains and SRH, the prevalence of poor health fell in a descending order, moving from the poorest to the richest wealth quintiles and from the lowest to the highest levels of education. The RII for SRH and all health domains (except for vision) was greater than 1 according to both wealth and education. For wealth-related RII, after controlling for the effects of age, sex, marital status and education, it remained greater than 1 and statistically significant for SRH and the sleep and energy, affect, pain and discomfort, and mobility domains only. Education-related RII was greater than 1 and statistically significant for SRH, interpersonal activities, cognition, pain and discomfort, and mobility.

Although it is difficult to compare our results with those of other studies because of the lack of similar such studies, they are consistent with the few that are available.

In a similar study, Hosseinpoor et al used the WHS of 2002-2004 to investigate the socioeconomic inequality of different health domains. On analysis, they too observed similar inequality results among low-income countries for most health domains. ${ }^{11}$ Inverse associations between poor SRH and education and wealth have been observed 
in other studies conducted in the city of Tehran as well. ${ }^{13}{ }^{22}$ Furthermore, our results are consistent with those of studies between SRH and SES conducted elsewhere in the world. ${ }^{23}{ }^{24}$ The association between SES and the cognitive aspect of health has been examined in a couple of studies, which indicate a better cognitive performance among individuals of higher educational levels. ${ }^{25}{ }^{26}$ Although the results of the latter studies are consistent with ours, we must keep in mind that most of these studies have been conducted on specific population, such as the elderly. Research on individuals' functional capacity indicates that people of lower educational level have lower functional capacity too, another finding similar to ours. ${ }^{27} 28$

Like other similar studies conducted in the past, our findings indicate that sleep disorders are more common among individuals living in poorer households (wealthwise). ${ }^{29}{ }^{30}$ However, unlike other studies, we found no association between sleep disorders and educational level. The reason behind this conflicting finding may be attributed to the method with which sleep disorders have been evaluated in previous studies compared with ours.

Unlike the current study, which indicated that socioeconomic inequality does not significantly exist in the vision domain, earlier studies show that visual disorders are less prevalent among groups of higher SES. ${ }^{11} 31$ A possible explanation behind this difference may be differences in the measurement of this variable (objective vs self-reported assessments). ${ }^{31}$

One of the principles recommended by the WHO Social Determinants of Health Commission to reduce inequalities is to understand and measure the problems and to assess the impact of the measures taken. ${ }^{32}$ The prerequisite of this task is to have appropriate evidence on different aspects of health and its distribution. ${ }^{32} \mathrm{SRH}$ integrates many health-related factors, so it may not show the differences in various health domains. ${ }^{33}$ Therefore, understanding the key components of health can provide policymakers with more indepth information to improve the different aspects of health and health as a whole.

The results of this study show that although inequality is seen in overall SRH, the inequality seen in some health domains is different from the inequality seen in overall $\mathrm{SRH}$, and that inequality does not exist in some domains. For example, although the prevalence of poor SRH in individuals with no formal education is almost three times that in individuals with academic education, the prevalence of interpersonal activities in individuals with no formal education is 6.4 times those with academic learning.

Having improved the total health indices in Iran, the Primary Health Care network and the recently implemented Health System Reform and Universal Health Coverage (UHC) have had a substantial role in decreasing inequality in the country. These policies, however, are being implemented at the population level. On the other hand, evidence has shown that interventions targeting disadvantaged populations could decrease the inequity on a great deal. Due to multidimensionality of the inequity, the results of the present study could be incorporated in the determination of educationally and economically disadvantaged populations, as well as in gauging future interventions. Consistent with the objectives of UHC, identification of the disadvantaged populations could also lead to better protection of these people against catastrophic health costs.

As one of the limitations, the health domains have been measured with self-rated data and clinical examinations have not been performed to evaluate them. The data came from a cross-sectional study; hence, a causal interpretation of the associations between socioeconomic factors and health should be done with caution. The distribution of households that refrained from responding was not equal across the different districts of Tehran. Nevertheless, the age and sex distribution of the participants did not significantly differ from those who participated in the survey $(\mathrm{P}=0.30)$. Since it is difficult to assess the income and costs of households in low-income and middle-income countries, ${ }^{34}$ their assets were used as a proxy of economic status. Because of lack of convergence in the SII full models (adjusted for age, sex, marital status, and wealth or education level), we have not reported the results of these models.

\section{CONCLUSIONS}

A considerable socioeconomic inequality was observed in different health domains in favour of groups of better SES. This inequality differed in different domains. Subsequently, the results suggest that policymaking aimed at attacking inequalities should pay attention to different health domains as well as to overall health. Since the magnitude of inequalities may change depending on the socioeconomic indicators used, it is essential that both education-related and wealth-related indices be measured to reflect socioeconomic inequality in order to plan effective interventions, and for this purpose it is necessary to conduct further quantitative and qualitative studies.

\section{Author affiliations}

${ }^{1}$ Department of Epidemiology and Biostatistics, School of Public Health, Student's Scientific Research Center (SSRC), Tehran University of Medical Sciences, Tehran, Iran

${ }^{2}$ Department of Epidemiology and Biostatistics, School of Public Health, Knowledge Utilization Research Center, Tehran University of Medical Sciences, Tehran, Iran ${ }^{3}$ Department of Information, Evidence and Research, World Health Organization, Geneva, Switzerland

${ }^{4}$ Department of Epidemiology and Biostatistics, School of Public Health, Zahedan University of Medical Sciences, Zahedan, Iran

${ }^{5}$ Research Center for Environmental Determinants of Health, Kermanshah University of Medical Sciences, Kermanshah, Iran

${ }^{6}$ Department of Epidemiology and Biostatistics, School of Public Health, Tehran University of Medical Sciences, Tehran, Iran

Contributors VB and SN made substantial contributions to the study conception and design, the acquisition, analysis and interpretation of data, drafting the manuscript, and revising the manuscript critically for important intellectual content. AF and MS contributed to the study design, acquisition and interpretation of data, 
and revised the manuscript critically. ARH and YS participated in statistical analysis, interpretation of data and revising the manuscript critically for important intellectual content. All authors agreed on the final manuscript prior to submission. All authors agreed to be accountable for all aspects of this work.

Funding This project was financially supported by the Vice Chancellor of Research at Tehran University of Medical Sciences (project no 25621-27-03-93).

Disclaimer The authors alone are responsible for the views expressed in this article and they do not necessarily represent the views, decisions, or policies of the institutions with which they are affiliated.

Competing interests None declared.

Patient consent Not required.

Ethics approval This study has been ethically approved by the Ethics Committee of Tehran University of Medical Sciences with code number IR.TUMS REC.1394.532.

Provenance and peer review Not commissioned; externally peer reviewed.

Data sharing statement Additional unpublished data are available by request to the corresponding author.

Open Access This is an Open Access article distributed in accordance with the Creative Commons Attribution Non Commercial (CC BY-NC 4.0) license, which permits others to distribute, remix, adapt, build upon this work non-commercially, and license their derivative works on different terms, provided the original work is properly cited and the use is non-commercial. See: http://creativecommons.org/ licenses/by-nc/4.0/

(C) Article author(s) (or their employer(s) unless otherwise stated in the text of the article) 2018. All rights reserved. No commercial use is permitted unless otherwise expressly granted.

\section{REFERENCES}

1. Murray CJ, Evans D. Health systems performance assessment: Office of Health Economics, 2006.

2. Hosseinpoor AR, Van Doorslaer E, Speybroeck N, et al. Decomposing socioeconomic inequality in infant mortality in Iran. Int J Epidemiol 2006;35:1211-9.

3. Mackenbach JP, Stirbu I, Roskam AJ, et al. European Union Working Group on Socioeconomic Inequalities in Health. Socioeconomic inequalities in health in 22 European countries. $N$ Engl J Med 2008;358:2468-81.

4. Khedmati Morasae E, Asadi Larl M, Setareh Forouzan A, et al. Avoidable socioeconomic inequality in mental health distribution in Tehran: Concentration Index standardization approach. Journal of North Khorasan University of Medical Sciences 2012;4:311-20.

5. Mackenbach JP, Kunst AE. Measuring the magnitude of socioeconomic inequalities in health: an overview of available measures illustrated with two examples from Europe. Soc Sci Med 1997:44:757-71.

6. Sadana R, Tandon A, Murray CJ, et al. Describing population health in six domains: comparable results from 66 household surveys. Geneva: World Health Organization, 2002.

7. Dowd JB, Zajacova A. Does the predictive power of self-rated health for subsequent mortality risk vary by socioeconomic status in the US? Int J Epidemiol 2007;36:1214-21.

8. Burström B, Fredlund P. Self rated health: Is it as good a predictor of subsequent mortality among adults in lower as well as in higher social classes? J Epidemiol Community Health 2001;55:836-40.

9. Nedjat S. Is Self-Rated Health a Good Indicator for Assessment of Population Health? Iranian Journal of Epidemiology 2015;10:89-96.

10. Delpierre C, Lauwers-Cances V, Datta GD, et al. Using selfrated health for analysing social inequalities in health: a risk for underestimating the gap between socioeconomic groups? J Epidemiol Community Health 2009;63:426-32.
11. Hosseinpoor AR, Stewart Williams JA, Itani L, et al. Socioeconomic inequality in domains of health: results from the World Health Surveys. BMC Public Health 2012;12:1):1.

12. Üstün TB, Chatterji S, Mechbal A, et al. The world health surveys Health systems performance assessment: debates, methods and empiricism. Geneva: World Health Organization, 2003.

13. Nedjat $\mathrm{S}$, Hosseinpoor $\mathrm{AR}$, Forouzanfar $\mathrm{MH}$, et al. Decomposing socioeconomic inequality in self-rated health in Tehran. J Epidemiol Community Health 2012;66:495-500.

14. Fatemeh Khalili SN, Baigi V, Yadegarfar G, et al. Persian Version of World Health Surveys Individual Questionnaire: A Validation Study. Journal of medical council of islamic Republic of Iran 2016;34:201-8.

15. Asfar T, Ahmad B, Rastam S, et al. Self-rated health and its determinants among adults in Syria: a model from the Middle East. BMC Public Health 2007;7:1.

16. Filmer D, Pritchett LH. Estimating wealth effects without expenditure data--or tears: an application to educational enrollments in states of India. Demography 2001;38:115-32.

17. Vyas S, Kumaranayake L. Constructing socio-economic status indices: how to use principal components analysis. Health Policy Plan 2006;21:459-68.

18. Asadi-Lari M, Khosravi A, Nedjat S, et al. Socioeconomic status and prevalence of self-reported diabetes among adults in Tehran: results from a large population-based cross-sectional study (Urban HEART-2). J Endocrinol Invest 2016;39:515-22.

19. Huisman M, Kunst AE, Mackenbach JP. Socioeconomic inequalities in morbidity among the elderly; a European overview. Soc Sci Med 2003;57:861-73.

20. Regidor E. Measures of health inequalities: part 2. J Epidemiol Community Health 2004;58:900-3.

21. Baigi V, Nedjat S, Fotouhi A, et al. Subjective social status in association with various health and socioeconomic indicators in Tehran. J Public Health 2016;24:497-503.

22. Montazeri A, Goshtasebi A, Vahdaninia M. Educational inequalities in self-reported health in a general Iranian population. BMC Res Notes 2008;1:50.

23. Kondo N, Sembajwe G, Kawachi I, et al. Income inequality, mortality, and self rated health: meta-analysis of multilevel studies. BMJ 2009;339:b4471.

24. Subramanian SV, Huijts T, Avendano M. Self-reported health assessments in the 2002 World Health Survey: how do they correlate with education? Bull World Health Organ 2010;88:131-8.

25. Cagney KA, Lauderdale DS. Education, wealth, and cognitive function in later life. J Gerontol B Psychol Sci Soc Sci 2002;57:P163-72.

26. Lee S, Kawachi I, Berkman LF, et al. Education, other socioeconomic indicators, and cognitive function. Am J Epidemiol 2003;157:712-20.

27. Sulander T, Martelin T, Sainio $P$, et al. Trends and educational disparities in functional capacity among people aged 65-84 years. Int J Epidemiol 2006;35:1255-61.

28. Zimmer Z, House JS. Education, income, and functional limitation transitions among American adults: contrasting onset and progression. Int J Epidemiol 2003;32:1089-97.

29. Arber S, Bote M, Meadows R. Gender and socio-economic patterning of self-reported sleep problems in Britain. Soc Sci Med 2009;68:281-9.

30. Grandner MA, Patel NP, Gehrman PR, et al. Who gets the best sleep? Ethnic and socioeconomic factors related to sleep complaints. Sleep Med 2010;11:470-8.

31. Emamian $\mathrm{MH}$, Zeraati $\mathrm{H}$, Majdzadeh $\mathrm{R}$, et al. Economic inequality in presenting near vision acuity in a middle-aged population: a BlinderOaxaca decomposition. Br J Ophthalmol 2013;97:1100-3.

32. Marmot M, Friel S, Bell R, et al. Closing the gap in a generation: health equity through action on the social determinants of health. The Lancet 2008;372:1661-9.

33. Bjorner JB, Fayers P, Idler E. Self-rated health. Assessing quality of life 2005:309-23.

34. Howe LD, Galobardes B, Matijasevich A, et al. Measuring socioeconomic position for epidemiological studies in low- and middleincome countries: a methods of measurement in epidemiology paper. Int J Epidemiol 2012;41:871-86. 